\title{
Explorando a racionalidade instrumental nas decisões da organização escolar
}

\author{
Maria João de Carvalho \\ Universidade de Trás-os-Montes e Alto Douro, Portugal
}

\section{Resumo}

Esta é uma abordagem à problemática da decisão e da racionalidade que the é inerente, com particular destaque para os aspectos constitutivos da racionalidade instrumental, visando explorar o seu alcance e os seus limites, ao mesmo tempo que se admitem outros modos de racionalidade. Foi dado especial relevo ao modo como a racionalidade instrumental é veiculada no âmbito da organização escolar e aos propósitos que pode servir, motivo pelo qual foi importante a identificação das determinações axiológicas, interesses, lógicas e objectivos que estão subjacentes a esta forma de racionalidade. Neste sentido fizemos uma reflexão em torno da decisão e da racionalidade instrumental considerando os comportamentos que Ihe estão associados, sem esquecer as práticas que fomenta e que promove na organização escolar.

Palavras-chave

Decisão; Racionalidade instrumental; Optimização; Controlo

\section{A dimensão do risco nas decisões}

Toda a especulação criada em torno da tomada de decisões não é indiferente ao problema de tomar as melhores decisões, como se de decisões sábias se tratassem, na medida em que os êxitos e fracassos organizacionais disso mesmo dependem. Todavia, seria excessivo se reclamássemos sempre resultados excelentes. Os resultados não dependem exclusivamente do 
decisor mas do indeterminismo a que a realidade está sujeita. Mesmo nos discursos que nos remetem para uma conceptualização de escola como instituição de serviços públicos, cuja "existência tende a ser encarada mais como um imperativo moral do que como um facto económico sujeito a cálculos de custo/benefício" (Drucker, 1997:195), os resultados práticos não deixam de ser considerados.

As decisões são sempre cruciais em menor ou maior grau, pelas consequências organizacionais que dela possam resultar. Com regularidade, à semelhança do que acontece em tantas outras organizações, a escola, ou melhor, os actores educativos que dela fazem parte, tomam decisões que, directa ou indirectamente, afectam o modo de a perceber, bem como o modo do seu funcionamento. Motivo pelo qual não é de estranhar que as decisões sejam categorizadas de acordo com o género e a ordem de importância.

E somos grandemente afectados por essas decisões mesmo quando não é uma atitude própria, mas concretizada por outros que a executam em nosso nome pelo poder que lhes é conferido. O risco que é inerente à decisão ${ }^{1}$ supõe a existência de um desagradável peso que muitos preferem não suportar ${ }^{2}$. Desta feita, como explica Lima no âmbito da participação das decisões, "recusam o preço que para tal poderiam ser forçados a pagar" (1998:188), remetendo esse papel para outros. Apesar de na categoria dos decisores encontrarmos aqueles para quem decidir representa uma actividade fascinante por obrigar à eleição de um particular caminho na encruzilhada dos possíveis produzindo, à custa da sua intervenção, novas realidades $^{3}$, há um outro tipo que se caracteriza por preferir copiar respostas dos esquemas gerais de comportamento proporcionados pelos paradigmas culturais em forma de normas ou tradições. Sentirá que a sua responsabilidade se dilui na da organização, motivo pelo qual se sente mais protegido. "É a decisão que revela de qualquer modo a organização a ela própria. Mostra qual é a natureza do sistema organizacional e como funciona" (ibid:: 201).

Qualquer decisão encontra a sua razão de ser na acção futura, é nesta que se justifica a própria decisão que, em si mesma, é também acção intencional, desencadeadora de novas acções, como se a concretização de uma acção implicasse a sua inserção na sucessão sem fim dos fenómenos, tornando-se elemento de uma nova decisão. É um acto que se concretiza no 
imediato, contrariamente ao seu impacto por gerar novas realidades (Lara, 1991: 59).

Apesar de considerarmos a existência de grande proximidade entre decisão e acção, a verdade é que tomar uma decisão não implica necessariamente passar à acção. A justificá-lo o facto de a acção não ser sincrónica da decisão e porque passar do "plano das orientações" para o "plano da acção" nem sempre é concretizável (Lima, op. cit.: 165).

Fazendo uso da conceptualização de não participação, proposta por Lima, somos levados a identificar a não-decisão, também, como aquela que não tem expressão na acção e que é levada a cabo por homens e mulheres que a não vêem como tarefa cómoda pela responsabilidade que a acção acarreta e pelas repercussões nem sempre fáceis de suportar. Enfrentar riscos impõe-se como um imperativo que muitos preferem não correr, o que em rigor legitimará a existência de uma decisão circunstancial, de envolvimento mínimo por parte dos sujeitos que as tomam (op. cit:: 188). Em causa está a decisão de "facto" em oposição aos "mínimos" de decisão a que estamos obrigados, pela simples razão de sermos homens e mulheres cuja existência não é outra coisa senão uma série ininterrupta de respostas às situações com que nos deparamos, o mesmo valendo para a organização escolar, e que, nesta linha de ideias, significará um acto humano e vital.

Será a reflexão em torno da decisão que conduzirá a questões do foro do comportamento de homens e mulheres que integram a organização, à possibilidade de desvendar as eventuais tensões que se insinuam a partir das suas práticas, a fornecer-nos os elementos necessários ao esboço de uma particular racionalidade. Para a classificação da racionalidade no âmbito da decisão parece ser indispensável convocar os sentidos inerentes aos comportamentos, bem como os objectivos e estratégias dos actores educativos. Segundo se adere e se veiculam certos valores, assim poderemos distinguir diferentes categorias de racionalidade.

Deste modo, considerando que o conceito de racionalidade tem uma evidente conotação técnica, importa enunciar que usufrui, simultaneamente, de uma componente política associada a determinados valores que as decisões, no âmbito da organização educativa, deixam antever. 
Nesta perspectiva, qualquer decisão arrasta consigo um modo de racionalidade a que não é alheio o processo de tomada de decisões e que se expressa na desocultação e apropriação dos valores que a consolidam. $O$ diálogo hermenêutico que com ela podemos manter denuncia a realidade ao mesmo tempo que a configura. Conhecer o processo de tomada de decisões a que a racionalidade instrumental se encontra veiculada é considerarmos que se concretiza em quatro momentos específicos, ligados entre si, por um movimento contínuo, uma sequência precisa entre as fases da concepção do projecto, nomeadamente a apreensão da situação que revela o problema, da deliberação, momento em que são avaliadas todas as alternativas possíveis de resposta, da selecção, que se traduz pela opção da solução óptima e, finalmente, da execução, que mais não é que a concretização da decisão. Processo, diga-se, que não permite ignorar os conceitos de linearidade e fragmentação, tão distantes da complexidade e imprevisibilidade do mundo real, e que deixa antever um modo de racionalidade a priori em que o pensamento precede a acção.

\section{O modo da racionalidade instrumental}

A racionalidade instrumental, que a burocracia weberiana preconiza, destaca-se pela preocupação fundamental pelos meios, pelos modos mais eficazes no alcance de determinados objectivos, relegando a questão das finalidades para um plano acessório, porque a pretensão de justificação não existe. Compreende, assim, a relação entre meio e fim, com referência à relação entre causa e efeito. Baseada na lógica desta relação dirige a sua preocupação à excelência dos métodos ${ }^{4}$ e busca, incessantemente, o 'menor meio' na procura da solução óptima para se atingirem os objectivos que esta racionalidade não discute e não contesta, nunca pondo em causa os valores em nome dos quais se actua. Neste sentido, é também uma racionalidade técnica, pois, "Sempre que se apresentar uma 'questão técnica' isto significa que existem dúvidas sobre os meios mais racionais. O critério de racionalidade para a técnica é, entre outros, também o famoso princípio do 'esforço mínimo': o resultado óptimo em comparação com os meios a serem aplicados" (Weber, 1991:38). A legitimidade dos fins fica, assim, relegada para o plano da indiferença, validando a tese de que determinado curso de acção é inequívoco "em grau máximo, quando o curso típico observado se baseia 
em motivos racionais orientados por fins (...), e quando a relação entre meio e fim, segundo a experiência é inequívoca (...). Nesse caso é admissível a afirmação de que, se se agisse de maneira rigorosamente racional, ter-se-ia de agir necessariamente dessa maneira e de nenhuma outra" (ibid:: 12). De facto, um dos indícios que nos permite reconhecer que nos mantemos aprisionados ao enredo da universalidade instrumental é considerarmos que o que é racional para um determinado sujeito também o é para um outro nas mesmas condições e circunstâncias. Considerar uma racionalidade que, mais do que negligenciar, marginaliza a temática da legitimação e validade dos fins, é adoptarmos uma posição de descomprometimento face a prioridades e a incompatibilidades que se estabelecem à medida que vamos impondo novas metas. Esta racionalidade, dita instrumental, só é representativa de uma parte da racionalidade, na medida em que só contempla a importância dos meios no alcance dos fins eleitos, o que não foi suficiente para se tornar um impedimento à sua hegemonia e ao seu entendimento como o único modo de racionalidade. Giroux reage a este modo de racionalidade cujos tentáculos não deixam de alcançar todas as áreas da actividade humana, pelo que também a educação se vê envolta por este espírito, pois "a teoria tem permanecido firmemente entrincheirada na lógica da racionalidade tecnocrática e tem-se ancorado em um discurso que encontra sua quintessência na tentativa de encontrar princípios universais de educação que sejam enraizados no espírito do instrumentalismo (...). Ao mesmo tempo esses relatos têm suprimido questões de relação entre poder, conhecimento e ideologia" (1986: 17).

Considerando este pressuposto, parece evidente que ficamos subordinados a uma única racionalidade que se universaliza a todos os sujeitos da acção, e, nesse sentido, os posicionamentos e as preferências diferenciadas que acentuam o princípio de heterogeneidade, que tão bem caracteriza os actores educativos, são negados.

Mas a optimização, inclusa nesta noção de racionalidade, está directamente relacionada com a questão do alcance que pode ter o esforço humano de racionalização, e que aqui se apresenta superando os efectivos poderes do sujeito humano. Porque, embora, imbuída de grande genialidade não pode ser aplicada às situações da vida real, pois transcende os seus próprios limites, o que faz dela utópica, absolutamente inatingível por parte 
daquele que não se julga Deus. É própria de um super-homem, e, por esse facto, Simon perspectiva-a como olímpica. Homens e mulheres da vida real não usufruem deste tipo de capacidades, mas sim de uma racionalidade "cerceada pela situação e pelos poderes de computação do homem" (1989: 47), que é, numa palavra, limitada. E, assim, reconhece que a racionalidade instrumental faz alusão a um tipo de ser humano que não existe na realidade, um super-homem com capacidades infinitamente superiores às que reconhecemos serem próprias de homens e mulheres. Para corroborar esta ideia o próprio autor perspectiva a teoria de Utilidade Subjectiva Esperada onde distingue entre "escolha óptima" e "escolha satisfatória", o que é claramente compatível com o entendimento que temos da racionalidade ideal e da racionalidade praticável, definidas pelo modo diferenciado de interpretar o todo da informação relativa a cada uma, em correspondência directa com as soluções encontradas. Na primeira, estas são absolutamente óptimas; na segunda, as melhores possíveis, consequência, de acordo com Rescher de "todo aquello que es relevante en relación con lo que podemos efectivamente realizar en determinadas circunstancias" (1993: 44). Com efeito, Simon duvida da escolha óptima que associa à racionalidade olímpica por fornecer ao homem as qualidades de absolutamente bem informado no que diz respeito ao possível curso da acção que empreende, bem como à possibilidade de prever todas as consequências daí resultantes, infinitamente sensível pelo facto de se prevenir contra toda a inconstância do ambiente e racional na medida em que a sua escolha óptima pressupõe o máximo de utilidade. Se é verdade que implica uma opção relativamente a todos os possíveis comportamentos "No comportamento real, porém, apenas uma fracção de todas estas possíveis alternativas é levada em consideração" (Simon, 1971: 79-80). Acresce que "A razão (ou a racionalidade) é, limitada, não só (...) porque o espírito humano é genericamente limitado (o que não é uma descoberta), mas porque é socialmente estruturado, determinado e, por isso, limitado" (Bourdieu, 2001: 262). Neste contexto, a decisão "is a best choice between 'almost right' and 'probably wrong' but much more often a choice between two courses of action neither of which is probably more nearly right than the other" (Drucker, 1970:146). Retira-se-lhes o carácter de absoluta superioridade que a técnica e a racionalidade lhes atribuem e, consequentemente, o epíteto de únicas e melhores decisões. A incerteza, a 
subjectividade e a satisfação serão elementos constitutivos da decisão agora susceptível a juízos de valor (Lima, 1998: 76). No entanto, e apesar da abordagem crítica feita à optimização inclusa na racionalidade instrumental feita por Simon, a verdade é que o autor mantém intacto o esquema clássico da decisão, pois continua a não pôr em causa a linearidade e a fragmentação.

A racionalidade instrumental exclui, sem restrições, a interferência da dimensão afectiva numa tentativa de erradicar qualquer resquício de erro que possa contaminar a acção organizacional ${ }^{5}$, produto, como esclarece Lima, "de uma determinada decisão claramente identificada, ou de uma escolha deliberada, calculada, em suma, racional" (1998: 69), o que explica a presença da impessoalidade nas relações, que o trato formal concretiza, por não facilitar qualquer consideração emocional. Impessoalidade que procede, como refere Aron, "em função das ordens abstractas de uma regulamentação estrita" (1987: 49) fundamento da universalidade, reconhecida na tentativa que o modelo burocrático faz de singularizar o que, à partida, seria diverso. $\mathrm{O}$ elemento humano transforma-se em mero acessório, retirando ao comportamento de homens e mulheres o estatuto de verdadeiro problema. Estes homens e mulheres são conceptualizados, de acordo com March e Simon, como instrumentos "passivos capazes de executar o trabalho e receber ordens, mas sem poder de iniciativa e sem exercerem influência provida de qualquer significação" (1966: 9). Torna-se efectiva a desvalorização a que os aspectos humanos da organização ficam votados e tudo em prol de uma eficácia instrumental. Nesta acepção de racionalidade, o comportamento dos actores organizacionais ao ser alvo de um planeamento rígido, aspecto fundante da previsibilidade, define-se enquanto actividade regulada por normas e regras que coordenam e, simultaneamente, controlam e antecipam, ao mesmo tempo que Ihes infunde constância, Ihes retira oscilações, produzindo comportamentos rotineiros. Os documentos escritos estarão na base dos comportamentos padronizados e na impessoalidade nas relações dos actores educativos. Em suma, os sujeitos são instrumentalizados ao serem reduzidos a meios ou modos de perseguir os objectivos organizacionais. Atribui-se-lhes uma configuração mecânica no que ao comportamento diz respeito, transformando-os num mecanismo especializado, visando servir os intentos do lucro, pelo aumento de produção. 
O conjunto de pressupostos apresentados pelo arquétipo da racionalidade instrumental faz a organização escolar assentar no princípio custo-benefício, no apelo a uma educação mais eficaz e, simultaneamente, mais barata, numa aproximação à conceptualização da escola como empresa educativa que não exclui a possibilidade de transformar os alunos em matériaprima e as escolas em fábricas ${ }^{6}$ e os diplomas em produtos estandardizados.

A Didáctica Magna. Tratado Universal de Ensinar Tudo a Todos de Coménio, escrita no século XVII, já apresenta claras evidências do alcance da racionalidade instrumental para a elaboração deste tipo de concepção de escola. O autor dá a conhecer o modo pelo qual se atingem finalidades tendo como suporte um "processo seguro e excelente (...) com economia de tempo e fadiga" (1996: 43). A dimensão económica, inerente ao comportamento é destacada, optimizar os benefícios tendo em conta o custo dos recursos está na mira do autor. Que os professores ensinem menos e os alunos aprendam mais pela abolição de trabalho considerado desnecessário, justifica a importância do método que ao ter como fundamento a certeza "seja impossível não conseguir bons resultados" (ibid.: 45). A sua proposta consiste em ensinar e a aprender com segurança, com facilidade e com vantajosa rapidez à custa de um método que se vislumbra como altamente racional. Acrescenta ainda que "há uma grande economia de fadiga e de tempo, quando uma só pessoa faz uma coisa, sem ser distraída por outras" (idid:: 136). A repartição do tempo e das matérias propicia uma progressiva aprendizagem.

\section{Da acomodação à emancipação dos actores educativos}

A passividade, a que induz o modo de racionalidade instrumental, é propagada pela transformação dos intervenientes na escola em meros receptores de corpos de informação enformados por determinados valores sem preocupação de justificação, modo de assegurar os fins, e que se consubstancia na afirmação de que os actores educativos são "consumidores passivos de conhecimento, ao invés de negociadores do mundo nos quais trabalham e agem" (Giroux, op.cit.: 235).

Este alto grau de formalização é sugestivo, na óptica de Hall, da "indicação das opiniões dos responsáveis pelo processo decisório sobre os 
membros organizacionais (...) encarados como incapazes de tomarem suas próprias decisões e exigindo um grande número de normas para orientar seu comportamento" (1984:68) obrigando ao acontecer desta categoria. Retira-se poder de iniciativa aos trabalhadores, porque não se Ihes reconhece capacidade decisória, relegando-a para os membros da direcção, os quais conferem à decisão um estatuto impermeável a qualquer discussão.

A centralização das decisões retira aos professores a possibilidade de emancipação. Só na e pela decisão poderemos constituir-nos como homens e mulheres intervenientes, capazes de fazer parte activa no mundo a que pertencemos ao invés de meros espectadores. Decidir é um sintoma de emancipação, é caracterizador de um espírito inquieto na procura da liberdade que a sua autonomia concretiza ao fazer-se sujeito da própria história. É o cidadão activo e útil para a sociedade, não o fiel vassalo que se reduz a um mero executante que pactua com as formas autocráticas de governos que só querem fomentar a apatia. Só o sujeito, com espírito de iniciativa produtora, será motivo de progresso para a sociedade, quer seja no plano das relações inter pessoais, ou no plano económico e cultural, aspectos que traduziriam uma revolução de âmbito global.

Para que tal objectivo se atinja é necessário questionar radicalmente o carácter supostamente imparcial e objectivo de toda a política educativa e de todos os processos que lhe dão origem, criticando e reflectindo sobre as razões de tais decisões, tornando-nos criadores e autores de decisões. Decidir supõe a intervenção dos professores e, por isso, uma concepção de governação de escola que se exprime na participação reflexiva, crítica e activa, ou seja, que não se limita a uma intervenção na discussão, mas ao acesso a decisões no âmbito do governo, da organização e administração da escola que em vez de os marginalizar os converte em sujeitos-agentes. Uma participação como "acto de ingerência e não a atitude do espectador que se limita a assistir ou, de mais ou menos longe, a contemplar" (Lima, 2000: 33). O que não acontecerá enquanto se mantiver uma lógica paternalista que, em rigor, não passa de um pseudo proteccionismo, que se justifica enquanto instrumento de subordinação pela necessidade da presença de uma autoridade simultaneamente externa e dominadora, ficando desculpabilizada a opressão, inviabilizando qualquer tentativa de ultrapassar aquilo que Freire define como "consciência ingénua" e que é reveladora de "uma certa simplicidade, tendente a um simplismo, na interpretação dos problemas, isto 
é, encara um desafio de maneira simplista ou com simplicidade. Não se aprofunda na causalidade do próprio fato" (Freire, 2001: 40).

É uma prática que subsiste enquanto não for repelida a transferência de responsabilidade e autoridade que ainda permite que a política educativa se faça nos gabinetes, sem se deixar contaminar pelas decisões "assumidas" pelos sujeitos que se encontram nas escolas contribuindo para a sua alienação, expressão acabada de uma hegemonia cultural, que se mantém desde o século XIX e que se foi paulatinamente consolidado ao longo dos tempos através de uma herança centralista e burocrática ${ }^{7}$. Este facto, que tem excluído os agentes educativos de participar na feitura das leis, tem contribuído para que todas as tentativas de mudança, que se tentam implementar no contexto da educação em Portugal, não sejam capazes de alterar, de modo significativo, a conjuntura vigente. Esta política, que mantém distanciados os educadores dos centros de decisão, tem-se revelado inoperante no que concerne à responsabilidade social e política. Tem, isso sim, conduzido ao conformismo, à ausência de sentido crítico, à ausência de vontade de intervir, visível em atitudes que só deixam lugar à repetição do que está prescrito e dado como certo, instaurando-se como meio mais eficaz para moldar os sujeitos à medida dos interesses da classe dominante, o que vai na linha defendida pelas teorias da reprodução.

\section{A competição e o mérito nas práticas educativas}

De acordo com alguns autores, a racionalidade instrumental, tecnocrática, tem sustentado a competição como uma componente educativa pela confusão fomentada entre progresso e eficiência, circunstância para se eliminarem discursos do âmbito do poder, da política e dos valores, corroborando a natural superioridade de uns sobre os outros e, consequentemente, permitindo que se estabeleça a competição entre indivíduos e grupos, reproduzindo a disposição dos mercados, como algo a preservar e a exaltar ${ }^{8}$. Os quadros de honra, classificações, testes de inteligência, diagnósticos psíquico/pedagógicos são alguns dos exemplos que permitem seleccionar e legitimar a exploração e as desigualadas sociais. Tudo se faz em prol da imagem representativa do mercado que o aluno deve assimilar e que, posteriormente, servirá como sua referência para determinar o seu 'preço' no mercado de trabalho (Oliveira, 1995: 136). 
De facto, a competição continua a ter um lugar nas práticas educativas promovidas por muitos professores em diversas escolas, recolhendo para si um estatuto que a coloca como princípio da educação pedagógica a destacar. Acolhe, desta feita, considerações que a caracterizam como particularmente saudável, na medida em que é apreendida como um instrumento fundamental para aumentar a eficiência, não obstante ser considerada como um princípio que contraria a educação humana ${ }^{9}$.

E se este mito ainda é caracterizador da postura dos actores da organização escolar, ele não pode deixar de ser um reflexo, ao mesmo tempo que reflecte, o mito do talento traduzido na ideia de um dom, na crença de uma genialidade que não está ao alcance de todos. Ora, esta convicção, se por um lado consegue alimentar o fenómeno da desigualdade e, paralelamente, o aparecimento de injustiças em termos da selectividade, naturalizando os rótulos de altamente talentoso, medianamente talentoso e destituído de talento, por outro reprime o processo da educação no sentido da emancipação, pois, como recorda Adorno, "o talento não se encontra previamente configurado nos homens, mas (...) em seu desenvolvimento, ele depende do desafio a que cada um é submetido" (2000: 170). Nesta linha de pensamento, pode-se defender que a competição deixa de ser nociva se entendida enquanto desafio que o educando trava consigo mesmo, na tentativa de realizar o mais possível as suas potencialidades, efectuando-se em termos de aperfeiçoamento educativo.

Contudo, a intenção é fazer destas componentes um meio para garantir os fins definidos através da eliminação de interesses conflituantes que possam colidir com interesses totalitários que são claramente os lucrativos, transformando os interesses particulares em universais. No contexto da organização escolar, este pseudo-consenso, localiza-se no âmbito do corpo curricular obrigatório, pré-determinado, que legitima as desigualdades e cria a ilusão de que as escolas são culturalmente idênticas, e num quadro de conhecimentos que aprisionam as relações sociais ao campo desse saber escolar, reduzindo a experiência da aprendizagem ao valor da sua exclusividade, iludindo $o$ acesso ao conhecimento e valorizando a banalidade, a adesão à comunicação de massas, a deferência.

Deste modo, a racionalidade instrumental, consegue constituir-se como elemento de manipulação ao lançar para o campo da irracionalidade 
todas as outras racionalidades que não se encaixem nos seus parâmetros e que embaraçam a sua constância. Esta racionalidade, que tenta colonizar todas as outras, e contrariamente a estas, não contempla qualquer teoria de aprendizagem que Ihe seja subjacente, forma de evitar limitações à tomada de decisões, não prevê uma aprendizagem feita à custa de erros ou qualquer forma de espontaneidade. Vota para o domínio da irracionalidade todas as outras lógicas que possam estar subjacentes a qualquer comportamento decisório que seja divergente dos princípios em que se funda.

Diríamos, a este propósito, que toda a irracionalidade mais não é que outra forma de racionalidade suportada por outros sentidos, por outras lógicas de acção que não têm, necessariamente, fins determinados e inalteráveis, porque toda a ideologia que reconheça o sujeito enquanto sujeito de acção não nega que muitas das suas finalidades se vão descobrindo na e pela acção. O que Friedberg corrobora quando escreve: "deve-se aceitar uma visão menos intencional e linear da acção humana. Esta não se resume aos objectivos que um indivíduo adopta ou julga perseguir. Deixa também espaço a coincidências, ao acaso e à descoberta" (1993: 51).

É neste enquadramento que a cultura do mérito se naturaliza e se intensifica através dos incentivos de recompensa alicerçados em um discurso de apelo à excelência das aprendizagens confirmada na elevação da pontuação dos alunos, nos resultados escolares no sentido da sua quantificação, na apreensão do conceito de sucesso e insucesso, na apresentação dos resultados das escolas subordinadas a uma lógica orientada para a quantificação do produto final e para a excelência como competência económica. No fundo, é o lado nem sempre visível para todos, de uma tendência inclusa no que Lima denomina como "Paradigma da Educação Contábil" que encerra uma panóplia de elementos conformes a uma política mercantil em educação e que revela a importância do "controlo da qualidade e a aferição da eficácia e da eficiência nas organizações educativas, entre outros" (2002: 91). Quando a aprendizagem e a formação parecem adquirir um sentido pragmático e competitivo e a escola se instrumentaliza para fins económicos e atribui protagonismo à educação enquanto instrumento de preparação para o trabalho, ao mesmo tempo que promove uma luta sob o desígnio da mão-de-obra, abandona os objectivos que incorporam os aspectos mais substantivos da perfectibilidade humana e 
da própria vida. Por este motivo, o sucesso da escola passa a ser conotado com o ajuste à economia e aos mecanismos de competitividade que aquela exige.

A qualidade tem vindo a ser confundida com um mecanismo utilizado no campo produtivo empresarial de acordo com as exigências do mercado. Esta lógica tem servido para intensificar as estratégias competitivas, próprias das organizações empresariais, traduzidas numa concepção de "justiça utilitarista e eficientista" (Estêvão, 2000:46). Cai no esquecimento que o conceito de qualidade pode servir, não só, no sentido de diminuir mas, também, de aumentar as desigualdades sociais, uma vez que este conceito vem sendo vinculado a uma lógica de mercado que limita a qualidade a um problema de custos de eficiência, que nunca tem em conta os excluídos, fazendo-nos concluir que nem sempre se apresenta como um direito de todos, mas um privilégio daqueles que se mostram mais capazes. Por isso, não é estranho que "Revalorizando concepções mecanicistas das organizações e da administração educativas, a educação contábil tende a centrar-se no cálculo e na mensuração dos resultados (desvalorizando os processos e os resultados mais difíceis de contabilizar), favorece a estandardização (em prejuízo da diversidade), apoia-se em regras burocráticas e em tecnologias estáveis e rotineiras, promove a decomposição e fragmentação dos processos educativos em unidades elementares e mais simples, passíveis de 'mercadorização'" (Lima, 2002: 107). Mas é esta a educação que conta porque pode ser avaliada transformando-se em verdadeira técnica de gestão e de controlo da qualidade. Dimensões que não são compatíveis com decisões reflexivas e críticas por estas estarem associadas, diz o autor, a "um processo lento e imprevisível, ambíguo e fluído, porque não garante a eficácia e porque, no limite, é irracional" (ibid:: 103).

Por isso, a resistência à democracia enquanto capacidade crítica, expansiva e criadora também se concretiza, no domínio da racionalidade instrumental, através da fragmentação das actividades escolares e da compartimentação do saber que actua como forma de dominação e controlo. Ao fragmentar-se a realidade em parcelas cada vez mais pequenas desvaloriza-se e evita-se a totalidade, o que não favorece a percepção da complexidade em favor do aprisionamento do sujeito à estreiteza da sua especialidade. Nesta medida, o especialista, aquele que sabe muito de pouco, 
ao saber cada vez mais de uma parte cada vez menor terá uma visão distorcida do todo e pode acabar por não se reconhecer nele, o que acabará por o condicionar e moldar de acordo com os parâmetros da classe detentora do poder. É um modo eficaz de conformar o indivíduo porque existe como que uma desconexão dos factos com a realidade, motivada pela opacidade da informação dando origem a uma realidade deformada porque avulsa, e, portanto, inacessível à compreensão.

Os interesses particulares podem, com facilidade, ser vinculados através dos currículos, dos currículos ocultos e dos processos de avaliação como instrumentos legitimadores de uma cultura única e uniforme, ligados que se encontram à lógica económica, impedindo o pensamento crítico e reflexivo, mas favorecendo uma visão distorcida da educação que parece encontrar-se subordinada a uma nova ideologia "na qual a democracia se torna um conceito económico em vez de político e na qual a ideia de bem público balança nas suas raízes" (Apple, 2000: 74). A ampla naturalização das políticas económicas, firmadas no sistema educativo, perturba a percepção dos professores que se tornam, normalmente, incapazes de constatar o elemento dominante a que a escola está subalterna, e passam a alterar a natureza da sua formação, acreditando que ela está ligada "à criação, estabilização e regularização de relações de poder e autoridade" (idid:: 94).

Naturaliza-se a situação de subalternidade relativa às determinações estabelecidas pelas instâncias superiores e declina-se qualquer experiência de debate e de análise dos problemas que poderiam proporcionar condições de autêntica vivência democrática. Mesmo porque a produção das políticas educativas se tem dado sem a anuência dos que estão comprometidos, directamente, com o trabalho educativo, o que, desde logo, diminui seriamente a possibilidade de um diálogo crítico que favorecesse a transformação da sociedade ao invés da adaptação ao mercado. Nesta linha, a escola é um instrumento ao serviço do estado autoritário e da autoridade económica, actuando de forma tutelar sobre os comportamentos no sentido de assegurar essa ordem ${ }^{10}$, não permitindo que seja questionada, ao mesmo tempo que restringe o espaço escolar ao predomínio de linguagens dominantes, eliminando o vocabulário associado a formas criativas de gerar o saber e reduzindo o pensamento ao seu uso instrumental. 


\section{Algumas práticas controladoras - A conformidade formal}

Este posicionamento está próximo do que se entende por cultura positivista que se mantém e que se estende, a nível da organização escolar, aos critérios de constituição de turmas e de organização de horários transferidos e reproduzidos de processos solidificados, próximos de processos administrativos instituídos, mas longe de qualquer apreensão pedagógica que sugira as reais necessidades escolares. Estamos no cerne do formalismo, de uma preocupação apenas teórica com os discentes. A escola cumpre a sua função reprodutora do sistema por permitir que as pessoas se transformem em espectadores descritivos e alienados, por não fomentar a "consciência do conflito", que possibilitaria averiguar as pluralidades e alterar as contradições com que se deparam. Estamos perante um confronto que se dá entre a organização da educação e aquilo a que Sérieyx entende por "revolução da inteligência", porque a preocupação incide muito mais sobre a estruturação de disciplinas que favorece a aquisição passiva do conhecimento, encoraja o trabalho solitário, sobrevaloriza a abstracção em prejuízo do concreto, que ensina um método cartesiano empobrecido que não é capaz de lidar com a complexidade de uma situação e não é facilitadora da integração dos conhecimentos, do desenvolvimento de espíritos livres (1993: 60-61).

As atribuições da Inspecção Geral da Educação nas escolas têm assumido uma orientação mecanicista de verificação dos procedimentos de ordem técnica, num sério elogio à acção burocrática da administração. Transformada numa fiscalização, assume um papel inquiridor sobre a capacidade de acomodação da actividade dos professores diante das regras estabelecidas, obrigando a um agir representativo da impessoalidade, uniformidade e rigidez, e valoriza as soluções fragmentadas pelos procedimentos burocráticos que se apresentam como que descontextualizadas porque não têm relação com o todo.

Neste âmbito, fica-se pela mera observância e verificação do cumprimento da lei, de onde advém o seu carácter mais punitivo que didáctico. Assim, a Inspecção Geral da Educação transforma-se num mecanismo de verificação segundo o espírito previsto pela administração central, que acentua e promove comportamentos acríticos e improdutivos, evidenciando as relações dominantes no interior da escola em vez de zelar, 
enquanto intermediário, pela construção de uma nova dinâmica de relações integradoras e práticas reformadoras que, dentro do possível, pudessem ser capazes de minorar o problema do insucesso. A apresentação de sugestões pedagógicas em termos de leccionação, o que implicaria formação nesse sentido, que aferisse sobre se os professores faltam nas suas aulas à sua função, ou seja, que estando na sala de aula não estão a ser professores, teria maior receptividade, pois veriam na sua função um objectivo congruente com os objectivos da educação.

Quase poderíamos afirmar que a grande maioria dos professores realizam determinadas actividades pelo receio de serem sancionados e julgados por uma acção inspectiva que pode aparecer inesperadamente e que tudo supervisionará, o que traduzirá e explicará o estatuto de big brother de que goza, ao mesmo tempo que reforça o sentido omnipresente do poder do centro.

A apreensão, que alguns negam, mas que parece existir, paralisa 0 professor e inibe algum desejo que poderia ter em procurar métodos mais eficazes, adoptando uma postura mais congruente com comportamentos previdentes e que caracteriza o seu modus operandi. Surpreendentemente, ao professor não se exige que produza efectivamente, que seja eficaz, que progrida em termos de métodos na tentativa de perscrutar aquele que possa permitir a verdadeira apropriação do que se aprende, recusando-se em assoberbar os alunos com imensa informação que deve ser decorada mas que, em seguida, imediatamente se esquece, passando a enfrentar a vida real com uma bagagem demasiado reduzida, mesmo ao fim de 12 anos de intensa aprendizagem. Importa mostrar que se conforma com as regras que lhe são impostas, sendo que a sua eficácia se traduz nesse conformismo, como se o problema residisse unicamente em demonstrar que existe uma submissão às normas e regras que recebem. Pouco parece importar se a realidade das coisas é completamente outra.

Resta a conformidade formal com o estabelecido e a necessidade de preparar para os exames que se baseiam em provas individuais e limitadas no tempo, contrariamente ao que se passa na vida real, e que transformados em método de controlo e em verdadeiro objectivo do trabalho escolar, em vez de serem apenas a sua verificação, inibem interrogações sobre se os conhecimentos que fornece são duráveis ou consistentes, como se a 
preocupação em indagar sobre o que fica no final do processo educativo não fizesse sentido, mesmo porque a inspecção não o julga sobre esse prisma. Por isso, por hipótese, deixam de ponderar sobre a possibilidade de uma outra educação que em vez de exigir que o educando atinja certos níveis antes de obter o seu certificado, garantisse antes que só saísse da escola após atingir certos objectivos. Se é o desenvolvimento de competências uma das preocupações essenciais da organização escolar, não parece que seja necessário que devam estar em relação directa com a idade ou com os exames a serem realizados em idades particulares na medida em que os ritmos de aprendizagem, há muito se sabe disso, se processam em tempos diferentes ${ }^{12}$.

Esta conjectura só tem o propósito de mostrar que a inspecção, à semelhança de outras formas de controlo, não encoraja a um pensamento ousado que se posicione perante o fundamental e não se renda a detalhes, que reflicta as condições de um pensar que confira prioridade aos porquês, ou ao porque não, em prejuízo do quê e do como, ou seja, que passe de uma racionalidade instrumental para uma racionalidade substantiva $e$ emancipatória.

A acção da inspecção, em termos globais, só verifica a conformidade formal do inspeccionado com os modelos pré-estabelecidos, não tem em conta a verificação de longo prazo. Daí que a atenção incida muito mais sobre os resultados formais que materiais. É caso para dizer que o uso contínuo deste tipo de poder desencoraja, em muito, iniciativas fundadas na intuição, que aqui adquire um sentido próximo do determinado por Stacey, por implicar trabalho árduo, que obriga a que os sujeitos se mantenham em permanente contacto com a realidade e que dispensem atenção aos factos observados com o objectivo de encontrarem novas alternativas levando-os a não restringirem a sua acção às formas existentes de fazer as coisas; sentido que muito se afasta de uma conceptualização de intuição como um súbito "golpe de génio" (1995: 381).

$\mathrm{Na}$ organização escolar também a avaliação se mantém à custa da padronização, condição necessária para que ela se realize, mas descurando que na escola há aspectos que não podem ser quantificáveis, esquecendo-se que as escolas têm diferenças, quanto mais não seja pelo contexto geográfico em que se situam, o que não é concordante com uma visão unificadora da 
realidade e com uma perspectiva cultural comum. A avaliação tem a desditosa capacidade para criar ilusões quanto à crença na igualdade, embora seja a primeira a legitimar desigualdades. A alienação, de acordo com a análise realizada por Hextall e Sarup, mais não é que o resultado de um processo de avaliação que ao estabelecer um valor como representativo de determinada tarefa está a determinar um "valor de troca", que se compara com o de outros e que se transmuta em classificações ou certificados, retirando ao trabalho realizado a possibilidade de ser apreendido pelo sujeito que o realizou (1977: 158).

Obviamente que esta apreciação contaria a ideia de que a avaliação contribui para a socialização dos actores educativos, funcionando como um mecanismo que prepara para as exigências dos futuros papéis que cada um desempenhará na vida real. Com efeito, de acordo com Enguita, "En la escuela se aprende a estar constantemente en trance de ser medido, classificado y etiquetado; a que todas nuestras acciones y omisiones sea susceptibles de ser incorporadas a nuestro registo personal; a aceptar ser objeto de avaluación y incluso a desearlo" (1990: 228).

Um desejo que reflecte o crescimento e a naturalização de um sentimento competitivo, que converte a classificação num factor decisivo ${ }^{12}$ enquanto instrumento diferenciador de êxito, princípios que legitimam as perspectivas que apoiam a ideologia do individualismo e nos levam a concluir a existência "de conexões bem reais entre a economia e a actividade de classificação e selecção realizada pela educação" (Apple, 1989:48). A verdade, é que a avaliação vai conquistando relevo à medida que a ideia de "mercado educacional" ganha protagonismo, é a ela que se recorre enquanto "a 'market signal' - a means by which the educational performance of teachers and schools, as well as students, can be judged" (Willis, 1992: 205).

Resumir a avaliação a uma técnica de medição, e excluir a dimensão política e ideológica, é um posicionamento que não é capaz de a reconhecer enquanto actividade política, é um posicionamento que negligencia a importância de, utilizando as palavras de Afonso, "verificar a que interesses serve e como é que esses interesses são representados ou respeitados" (1999:52). Porém, a avaliação não é um processo negativo em si mesmo, dependerá sempre do interesse que serve. Por isso, não podemos descurar a sua importância, enquanto processo pedagógico utilizado na gestão, quando 
influencia as aprendizagens e fornece ao professor informações relevantes sobre a sua actuação, enquanto profissional, e sobre os métodos pedagógicos que utiliza.

A padronização curricular, os critérios de avaliação e a sua assumida contabilidade, os projectos educativos, consolidados como actividades de planificação, servem os propósitos de uma decisão mais do âmbito do conformismo que do questionamento, ao valorizar a dimensão técnica em detrimento da reflexiva. Depreende-se que muitas das decisões que ocorrem em contexto escolar têm como suporte uma racionalidade que obedece à lógica do mercado, como corrobora Illich quando escreve que "o resultado do processo de produção curricular assemelha-se ao de um qualquer processo mercadológico moderno. É uma embalagem de significados planejados, um pacote de valores, um bem de consumo cuja 'propaganda dirigida' faz com que se torne vendável a um número suficientemente grande de pessoas para justificar o custo de produção" (1976: 79).

A racionalidade instrumental é a concretização da hegemonia da cultura dominante, pois o objectivo é educar para a adaptação e reprodução das estruturas sociais como garante do próprio sistema, fazendo do sujeito um mero espectador de tudo o que vai acontecendo em seu redor.

Certo, é que a este modo de racionalidade, altamente formal, baseada na lógica de relações entre meios e fins, nem sempre produz os seus frutos. As consequências imprevistas, que resultaram da sua aplicação, levam-nos a concluir que nem sempre a solução formal que apresenta é capaz de tudo prever e regulamentar, denunciando o seu carácter falível.

\section{Notas}

1 Riscos que podem ultrapassar a esfera factual. Qualquer decisão contém um grau diferenciado de desconforto muitas vezes com origem no empenhamento emocional que a mesma acarretou (Crozier, 1983:65)

2 Peso que pode resultar numa espécie de paralisia perante a acção quando os potenciais decisores se debruçam em profundidade sobre as situações decisórias e "su propia lucidez les hace advertir que les faltan elementos que ellos consideran importantes para tomar la decisión. (...) llegan a posiciones de permanente inhibición y de no compromiso con lo real. Es lo que constatamos frecuentemente en los que se refugian en su estatuto de intelectuales puros" (Lara, 1991:22). 
3 Conforme refere Lara: "Esa mezcla de poder y de riesgo que implica la actividad de decidir permanentemente es algo que fascina a algunas personas, como un fruto agridulce, de sabor ambiguo, pero fuerte" (ibid.: 23).

4 "A 'técnica' de uma ação significa para nós a suma importância dos meios empregados, em oposição ao sentido ou fim pelo qual, em última instância se orienta (in concreto); a técnica 'racional' significa uma aplicação de meios que consciente e planejadamente está orientada pela experiência e reflexão e, em seu máximo de racionalidade, pelo pensamento científico" (Weber, 1991: 38)

5 "A consideração racional de uma pessoa sobre se determinada acção é proveitosa ou não para determinados interesses dados, em vista das consequências a serem esperadas, e a decisão resultantes são coisas cuja compreensão nem por um fio é facilitada por considerações psicológicas" (ibid:: 12).

6 "[...] numa escola, as matérias seriam os alunos, os materiais didácticos, os livros ( ...) a escola é uma fábrica, com linhas de produção empenhadas em fabricar um certo número de crianças idênticas, todas com características comuns" (Cortis, 1980: 138-139).

7 Com efeito, durante a apresentação dos trabalhos levados a cabo pela CRSE e da discussão da LBSE, os professores, apesar do epíteto de agentes privilegiados na reforma, só seriam chamados quando já pouco havia para decidir, sendo remetida a sua participação para a fase de execução, situação que favoreceu a desmobilização. Como refere Nóvoa, "os professores, enquanto corpo profissional, têm tido uma participação reduzida na reforma do sistema educativo português; os 'grupos políticos' e os experts pedagógicos' têm liderado este movimento acentuando o fosso que separa os actores dos decisores" (1992: 83).

8 Como lembram Baudelot e Establet: "L'émulation et le culte de la compétition représentent déjà à l'intérieur de l'école la concurrence que règle le marché du travail" (1971: 273).

9 É necessário, adverte Adorno, eliminar os mitos que o próprio sistema educativo constrói na tentativa de garantir o princípio da igualdade e da justiça na sociedade como ideário de democracia. (2000: 161)

10 Controlo, eficiência, exploração da natureza, tecnologia avançada, progresso, produtividade, hierarquia e outros, são valores de tal forma naturalizados que raramente são alvos de uma análise crítica. A inexistência de um carácter problematizador poderá produzir um efeito de desordem entre o interesse administrativo e o interesse geral adulterado pelos interesses dominantes. (Alvesson, 1993: 46-47).

11 É curiosa a justificação de Handy sobre o limite de idade. Faz notar o autor que: "Só pode ser por razões de conveniência administrativa que as escolas, de todas as nossas instituições, continuam a ser as mais ligadas à idade. O efeito é fazer metade dos nossos jovens sentirem que são fracassos"(1994: 194).

12 A este propósito Iturra recorda-nos que a entrada na escola dissocia o indivíduo do seu contexto, em particular quando o isenta "da prática de construir relações em base emotiva, para as construir em base competitiva cujo salário é a nota (1990: 48). 


\section{Referências}

ADORNO, Theodor (2000). Educação e Emancipação. São Paulo: Paz e Terra.

AFONSO, Almerindo (1999). Políticas Educativas e Avaliação Educacional. Braga: Instituto de Educação e Psicologia/Universidade do Minho.

ALVESSON, Mats (1993). Cultural Perspectives on Organizations. Cambridge: University Press.

APPLE, Michel W. (1989). Currículo e Poder. Educação e Realidade. Vol.14, № 2.

APPLE, Michel, W. (2000). Política Cultural e Educação. São Paulo: Editora Cortez.

ARON, Raymond (1987). As Etapas do Pensamento Sociológico. Brasília: Livraria Martins Fontes Editora.

BAUDELOT, Christian \& ESTABLET, Roger (1971). L'Ecole Capitaliste en France. Paris: Maspero.

COMÉNIO, João A. (1996). Didáctica Magna. Tratado Universal de Ensinar Tudo a Todos. Lisboa: Fundação Calouste Gulbenkian.

CORREIA, José A. (1999). As Ideologias Educativas em Portugal nos Últimos 25 Anos. Cadernos do Correio Pedagógico, no 48, pp. 81-110.

CORTIS, Gerard (1980). O Contexto social no ensino. Lisboa: Livros Horizonte.

CROZIER, Michel (1983). A Sociedade Bloqueada. Brasília: Editora Universidade Brasília.

DRUCKER, Peter F. (1970). The Effective Executive. London: Pan Books.

DRUCKER, Peter F. (1997). Inovação e Gestão. Lisboa: Editorial Presença.

ENGUITA, Mariano F. (1990). La Cara Oculta de la Escuela. Educación y Trabajo en el Capitalismo. Madrid: Siglo Veintiuno.

ESTEVÃO, Carlos (2000). Repensar a autonomia das escolas à luz de uma cartografia da justiça. IEG Informação, Ano 8, no 1, pp. 35-50.

FRIEDBERG, Erhard (1993). O Poder e a Regra. Dinâmicas da Acção Organizada. Lisboa: Instituto Piaget.

GIROUX, Henry (1986). Teoria Crítica e Resistência em Educação. Para além das Teorias de Reprodução. Petrópolis: Ed. Vozes.

HALL, Richard H. (1984). Organizações, Estrutura e Processos. Rio de Janeiro: Editora Prentice-Hall do Brasil.

HANDY, Charles (1994). A Era do Paradoxo. Dar Sentido aos Desafios do Futuro. Mem Martins: Edições Cetop.

HEXTAL, Ian \& SARUP, Madan (1977). School Knowledge: evaluation and alienation. In M. Young \& G. Whitty (Orgs.), Society, State and Schooling. London: Farmer Press.

ILLICH, Ivan (1976). Sociedade sem Escolas. Petrópolis: Editora Vozes.

ITURRA, Raul (1990). Fugirás à Escola para Trabalhar a Terra. Lisboa: Escher.

LARA, Blas (1991). La Decisión. Un Problema Contemporâneo. Madrid, Espasa Calpe.

LIMA, Licínio (1998). A Escola como Organização e a Participação na Organização Escolar. Um Estudo da Escola Secundária em Portugal (1974-1996). Braga: Universidade do Minho / Instituto de Educação e Psicologia. 
LIMA, Lícinio (2002). O Paradigma da Educação Contábil: políticas educativas e perpsectivas gerencialistas no ensino superior. In L. Lima \& A. Afonso (Orgs.), Reformas da Educação Pública. Democratização, Modernização, Neoliberalismo. Porto: Edições Afrontamento, pp. 91-110.

MARCH, James \& SIMON, Herbert (1966). Teoria das Organizações. Rio de Janeiro: Fundação Getúlio Vargas.

NÓVOA, António (1992). A pedagogia, os professores e as escolas: Há tanta coisa a mudar nestes anos 90. Educação em Portugal: Anos 80/90. Porto: Edições Asa, pp. 81-95.

OLIVEIRA, N. R. (1995). Teoria Crítica e Educação. Petrópolis: Vozes.

RESCHER, Nicholas (1993). La Racionalidad. Una Indagación Filosófica sobre la Naturaleza y la Justificación de la Razón. Madrid: Editorial Tecnos.

SÉRIEYX, Hervé (1993). O Big Bang das Organizações. Lisboa: Publicações D. Quixote.

SIMON, Herbert (1971). Comportamento Administrativo. Rio de Janeiro: Fundação Getúlio Vargas.

SIMON, Herbert (1989). A Razão nas Coisas Humanas. Lisboa: Editora Gradiva.

STACEY, Ralph (1995). A Fronteira do Caos. Venda Nova: Editora Bertrand.

WEBER, Max (1991). Economia e Sociedade. Fundamentos da Sociologia Compreensiva. Vol. I, Brasília: Editora Universidade Brasília.

WILLIS, Deborah (1992). Educational assessment and accountability: a New Zealand case study. Journal of Education Policy. Vol. 7, no 2, pp.197-215. 


\section{EXPLORING THE INSTRUMENTAL RATIONALITY IN THE DECISIONS OF SCHOOL ORGANIZATION}

Abstract

This is an approach towards the problem of decision making and the rationality which is inherent to it. Constitutive aspects of instrumental rationality are highlighted with the objective of exploring its limits and boundaries whilst admitting other modes of rationality. Importance was given to the way instrumental rationality is propagated within school organization and also to the purposes that it can help. That is why it was important to identify the axiological determinations, interests, logics and objectives that are underlying this form of rationality. In this sense a reflection was made on both decision making and instrumental rationality regarding those behaviours associated to it plus the practices that it stirs up and promotes in the process of school organisation.

Keywords

Decision making; Instrumental rationality; Optimization; Control 


\section{EXPLOITANT LA RATIONALITÉ INSTRUMENTALE DANS L'ORGANISATION SCOLAIRE}

Résumé

C'est un abordage à la problématique de la décision et de la rationalité qui lui est inhérente, avec une relevance particulière pour les aspects constitutifs de la rationalité instrumentale qui visent explorer son objectif et ses limites, en même temps, qu'on peut admettre d'autres formes de rationalité. Nous avons mis en évidence, plus particulièrement, la façon dont la rationalité instrumentale est amenée dans le domaine de l'organisation scolaire. Nous avons, également, donné une grande importance à l'identification des déterminations axiologiques des intérêts, des éléments logiques et des objectifs qui sont inhérents à cette forme de rationalité, étant donné que ceuxci étaient l'un des motifs auxquels nos propos devaient servir. Dans ce sens nous avons fait une réflexion autour de la décision et de la rationalité instrumentale en considérant les comportements qui en sont associés, sans oublier les pratiques qui encourage et qui favorise dans $I^{\prime}$ organisation scolaire.

Mots-clé

Décision; Rationalité instrumentale; Optimisation; Controle

Recebido em Julho/2008

Aceite para publicação em Abril/2009 